\title{
The cultural literacy curriculum system optimizing research of communication and media major at colleges in network era
}

\author{
Jie Cai \\ Nanchang Institute of technology, Nanchang, Jiangxi Provice,330038 \\ 103006664@qq.com
}

Keywords: Network era, Communication and media major, Cultural literacy, Curriculum system

\begin{abstract}
In network era, the communication and media industry is facing a new ecological media integration. It has put forward plenty of new requirements on its business philosophy, media products, personnel literacy and other aspects. Facing the fast media development, the colleges and universities as the main base of media talents training, the traditional teaching system of them has been difficult to adapt to the needs of market talents. Optimizing the curriculum system, improving the teaching mode, constructing the new media practice teaching platform, and enhancing the cultural talents of the media in the network era are the urgency matter. This paper puts forward the scheme of optimizing design to the cultural literacy curriculum, which is on the analysis results of the media professionals training programs in colleges and universities nationwide.
\end{abstract}

\section{Introduction}

At Internet era, the traditional media both facing the Internet media competition and the dependent on the development of the Internet at the same time. Only the integration of this two is development direction of the media era. The rapid development of the Internet has also brought some problems. The low threshold of Internet media information access makes the dissemination of information distortion, and even kitsch. In this context background, both of the Internet media and the traditional media need more high quality professionals. This requires the media professionals training in colleges and universities must adapt to the development of the times. To strengthen the cultivation of cultural accomplishment, optimizing the curriculum system is an important part of the research on the curriculum of media major in colleges and universities.

Cultural literacy has very broad scope, including human cultural tastes, knowledge horizons, emotional attitudes, aesthetic taste, ideas, moral cultivation and the state of mind. The world view, outlook on life, values of person are the core and signs of cultural literacy. Since the 18th CPC National Congress, the Party Central Committee put forward the socialist core values, emphasizing the improvement of civil literacy is the important force to promote the modernization process of the Chinese nation.

\section{The training of media talents must meet the needs of the time development}

The development of the Internet is so fast, the development of all walks of life are inseparable from it, even the daily life of ordinary people, basic necessities are inseparable from the Internet. In such an Internet era, each individual person may become the information source of the Internet. Numerous self-media speed up the spread of information and also has brought many problems for internet spread, such as cyber violence, cyber rumors, cyber pornography, cyber false news, and so on. The spread of these content is undoubtedly affecting the stability of society and the progress of human civilization. For the Internet media regulation and governance, it not only requires the constraints of the laws and regulations of the Government, but also need to improve the self-discipline and rigorous work attitude of the media talent in this industry. This means that the training of media talent must also keep pace with the times, to adapt to the needs of the Internet era development. 
The integration of Internet and traditional media ushered a new media era. This time era background put forward new requirement to the media personnel training. Traditional media not only need the practical talent who are familiar with the traditional program production and operation, also need the technical personnel who understanding the characteristics of internet, the more important is have all media talent who have higher cultural quality. Facing the shortcutting of the internet media information dissemination, such as the anonymity, unhealthy, unjust and unreasonable. The emphasis of media professional training program research should be focus on the optimal design of cultural literacy curriculum. On the basis of the traditional history and politics, colleges should pay more attention to the cultivation of students' humanistic accomplishment, scientific and technological accomplishment and artistic accomplishment.

\section{The essential cultural literacy of the media talent at this internet era}

\subsection{Human Quality}

Human quality include literature, history, philosophy, and innovation. Among them, literature literacy is an important part of human quality. It refers to the level of writing, communication or communication during the person's cultural activity. The media talent at the internet era should not only understand the traditional literature, but also familiar with the network literature. Reading can not only cultivate a person's moral cultivation, but also can help people to establish a correct outlook on life, world outlook, and good behavior. Facing the low degree credibility of Internet information, local TV column content homogeneity and other serious problems, it must improve their literature literacy, not only can enhance the competitiveness of traditional TV columns, and also could improve the value of Internet media information.

The human life changes bring by the Internet like as the 20-year-ago science fiction movie makes us marvel. Now people can call by watch, watch the video mobile, use mobile payment, ride share bike, and even through the VR technology to visit the virtual reality news scene. All this is derived from the guidance of innovative thinking. Under the Internet age, the development of traditional media will face a huge challenges. Traditional film and television works only rely on the Internet to spread is unable to meet the needs of Internet users' audio-visual needs. Younger Internet users has fragment viewing habits, while they are more emphasis on the interaction. These all require media talent to use Internet thinking to innovate program form. For example, pure network variety show "please take care of my refrigerator" is a star variety show, which introduce by Tencent video from South Korea. On the basis of the original, it give up to play at the traditional media and the use network platform broadcast. And it developed a "chef proposal" link, these new changes make the network boom a new variety of craze. The integration of the Internet and traditional media will need more high-quality media talent to use innovative ideas to develop new program form.

\subsection{Artistic Accomplishment}

The various major direction of media majors are attached to first-level discipline "art" category. It can be seen that the requirements to the artistic accomplishment of the media professionals should be higher than other categories of liberal arts discipline. Whether it is film, television or radio, it is a modern electronic technology with the art style. The media major is the specialized major on the creation of film, television and radio programs. Aesthetics is an essential artistic accomplishment for every artistic creator. Aesthetic is the specific ability of the aesthetic subject to appreciate, identify and judge the beauty and ugliness. It is the comprehensive performance of aesthetic perception, feeling, imagination, judgment and creativity. As the media talent of the new times, in order to meet the audiovisual psychological demands of the young internet audience, they must enhance their aesthetic ability. TV media and Internet media has its specific style positioning. For example, the screen style will use some avant-garde elements, with more bold color, more saturated color, more bright color. The clothing style of moderator will be more fashionable and personality. Language expression will be more hip hop or closer to life, and network language and network 
culture will filling in them. The TV column packaging, the host image, the latter part of the program editing, and so on, the entire program of audio-visual content should bring the beauty feelings to the audience. Therefore, as a media talent, whether it is the host, director, camera, later, animation effects, music, audio and other staff need to enhance their aesthetic ability to express the beauty screen and sounds.

\subsection{Scientific Literacy}

In 1995, China announced the decision to implement the strategy of revitalizing the country, the science and technology is still the first productive force. The public's scientific literacy is related to the comprehensive national strength. Nowadays, the science and technology is increasingly affecting our life, a person's scientific literacy level is not irrelevant. It has begun to affect the quality of human life in modern society, and at the same time constantly affecting and changing the values and views of the people about many issues. As a qualified media talent is more need to cultivate scientific literacy to arm their minds. So that they can make better science and education programs to serve the ordinary people, to improve the scientific literacy of the whole nation. Such as large-scale science reality show "the strongest brain", large-scale popular science column "into the science", as well as the first large-scale scientific experimental program "fuel to the future" and other TV columns, all of these need high-quality media talent attend into the production, especially with high scientific literacy of media talent. Scientific literacy has three parts: scientific knowledge, scientific methods and science function to the society. In these three parts, the "scientific method" is strangeness for most ordinary citizens. But "refueling for the future" and "is it true?" this kind of scientific experimental column makes the audience closer to science, and even feel that science is very interesting. Is the Internet a high tech product? In this era of popular science, media talent must have a better scientific literacy in order to make good use of science, in order to better spread the science.

\section{The advantages and disadvantages of the existing talent curriculum system}

During the writing process of this paper, the author look up a number of media professional training program of different colleges and universities. Media professional generally include: journalism direction, communication direction, drama film and television direction, radio and television director direction, broadcast and presided over direction, advertising design art direction, and so on. During the look up, the author focus on the general curriculum and professional courses set up of each direction. The research results shown that there are some commonalities in the establishment of the cultural quality curriculum, which are manifested in the advantages and disadvantages of the whole curriculum system.

The advantage is that most of the colleges and universities are attached great importance to the media talent humanistic training in the design of personnel training programs. For example, the each professional direction of Nanchang University School of Communication has set up courses such as "Selected reading of Ancient Chinese Works", "Selected reading of Chinese Modern Literature", "Selected reading of Foreign Literature" and "Chinese Philosophy". Jiujiang College media major have opened a "Chinese cultural history", "Chinese literature", "film and television literature" and other courses. Guizhou Nationalities College opened "modern literature", "aesthetic basis", "cultural anthropology" and other courses. These courses are set up to improve the cultural accomplishment of media talents. .

However, there are still some shortcomings in the talent training program. First, most of the colleges and universities are attach importance to the cultivation of literary literacy, while ignoring the innovation awareness training of media talent. Innovation is the soul of the any industry development. Second, ignoring the cultivation of scientific literacy. In many college teachers' viewpoint, "science" and "science and technology" should be the content learn by the science students. From the direction of this year's Hi-Tech reform, it can see in the future it will abolish the liberal arts division, and the current media professionals program is also recruiting the both literary and scientific students. So the future media talent must strengthen its "scientific literacy" to 
understand the forefront science knowledge and new inventions, understanding science celebrities of the global industry, and familiar with science and technology on human life impact. And finally realize that using the science and technology to disseminate scientific knowledge and realize the rejuvenation of science and education. Third, ignoring the cultivation of artistic accomplishment. Only the advertising design professional direction will open the "aesthetics" course, the other professional direction are ignored students' aesthetic taste cultivation and language expression art training.

\section{Culture literacy curriculum system optimizing program of the media talent}

In summary, at the Internet era, there are put forward more new requirements to the training of media professionals. Cultural literacy curriculum system is divided into three parts. First is humanistic accomplishment, including literature, history, philosophy, traditional culture and innovation consciousness. Second is scientific literacy, including contemporary scientific achievements and history of Chinese and foreign science and technology. Third is artistic literacy, including the cultivation of aesthetic taste and language art training. The corresponding courses of this three system are as follows:

\begin{tabular}{|c|c|c|}
\hline Human Quality & Scientific Literacy & Artistic Accomplishment \\
\hline Modern Chinese Literature & $\begin{array}{c}\text { History of Chinese and foreign } \\
\text { science and technology } \\
\text { development }\end{array}$ & Aesthetics \\
\hline Modern Chinese history & $\begin{array}{c}\text { Records of Contemporary } \\
\text { Scientific Achievements }\end{array}$ & $\begin{array}{c}\text { Introduction to Art } \\
\text { Expression }\end{array}$ \\
\hline Marxist Philosophy & & \\
\hline Creative thinking training & & \\
\hline Social etiquette & & \\
\hline
\end{tabular}

The above content is based on the full study of the cultural literacy curriculum set up. The optimized content of it in four aspects: The first is to add up the "creative thinking training" course, emphasizing the sense of innovation of college students. Whether it is online media operations, management, or network programming planning production, no sense of innovation is not competitive. The second is to add up the content of the science literacy course. This is also the characteristics of the Internet age, no technology no Internet age. Scientific knowledge can broaden the knowledge of students. Understand some famous scientists and technology development history can inspire students' scientific enthusiasm, and also stimulate their creative thinking. Third, is to add up the "language art and performance." The cultural literacy level is the write or speak out ability perform through the process of interpersonal communication. This is the only courses in this three system, which is teach students the charm of language art and language expression method. Fourth is add up the "social etiquette" course. The past humanistic literacy training did not pay attention to aspects. Although in Internet era, the Internet media content dissemination and sales process are full of complex interpersonal relationships, social etiquette can help students convergence social better.

\section{Conclusion}

At Internet era, the integration of traditional media and new media has been formed. The cultural accomplishment cultivation to the media talent at the new era must bring the highly attention by the teaching executives of each university. Humanistic quality, scientific literacy and artistic accomplishment constitute three aspects of media culture curriculum system. Causing the different colleges has different professional direction, different personnel training objectives, and different teaching level, these will affect their cultural quality curriculum provision. The specific curriculum arrangements of above three aspects should also be taught in accordance with their aptitude, and 
advancing with the times. So that the future integration media could have a healthy and harmonious development.

\section{Acknowledgements}

The General project of the 2016 Jiangxi Province Educational Sciences 13th Five-Year Plan task in Colleges and Universities. Item No. 16YB163.

\section{References}

[1] ZHANG Yuneng. On the Aesthetic Education of Man [z].Jiangsu Yilin Press. 2012

[2] YU Xiliang. The present situation and cultivation countermeasure research of undergraduate media accomplishment [J]. Shandong Normal University. 2007

[3] WANG Baoyan. Educational problem research of the undergraduate media accomplishment [J]. Hebei Normal University. 2015

[4] ZHAO Huicai. Viewing colleges' curriculum provision of media major from the communication theory accomplishment viewpoint [J]. Art Science and Technology. 2016

[5] WANG Yong. The creative research of the media talent cultivation mode at colleges under the media integration background [J]. Shandong Normal University. 2011 